\section{Subtrocar for Removing a Gallbladder from the Abdominal Cavity}

Recent advances in laparoscopic cholecystectomy have enabled us to perform the procedure using three $3 \mathrm{~mm}$ or $5 \mathrm{~mm}$ trocars for operative instruments and a $10 \mathrm{~mm}$ trocar for the laparoscope [1,2]. A small-diameter laparoscope is necessary to perform the procedure when removing a gallbladder from the abdominal cavity. Small-diameter laparoscopes, however, are expensive, and still give poor imaging [3]. We have developed a subtrocar which enabled us to extract the gallbladder without using a small-diameter laparoscope.

As shown in Figure 1, the tip of a subtrocar is designed to allow it to be inserted alongside a $10 \mathrm{~mm}$ reusable trocar without damaging the surrounding tissue. Thereafter, $5 \mathrm{~mm}$ grasping forceps are inserted through the subtrocar and used to grasp the gallbladder. The gallbladder is observed using the laparoscope (Figure 2), and is pulled out from the abdominal cavity using the subtrocar and the $10 \mathrm{~mm}$ trocar used for the laparoscope.

We performed the procedure in 17 patients between 31 August 1998 and 9 August 2000. In one patient, the gallbladder slipped off from the grasping forceps during removal from the abdominal cavity, and the patient showed mild subcutaneous bleeding at the operative wound. Another two patients also had evidence of mild subcutaneous bleeding, which resolved without special treatment. In the other patients, the gallbladder was removed safely without any complications. We conclude that the subtrocar is a useful instrument for performing laparoscopic cholecystectomy with small-size trocars.

\section{S. Kakizoe ${ }^{1}$, Y. Kakizoe ${ }^{1}$, S. Kase ${ }^{1}$,}

M. Ishida ${ }^{1}$, H. Kakizoe ${ }^{2}$, T. Kakizoe ${ }^{2}$, K. Kakizoe ${ }^{1}$

${ }^{1}$ Dept. of Surgery, Ilikai Medical INC. Kakizoe Hospital, Hirado, Nagasaki, Japan

${ }^{2}$ Dept. of Medicine, Ilikai Medical INC. Kakizoe Hospital, Hirado, Nagasaki, Japan

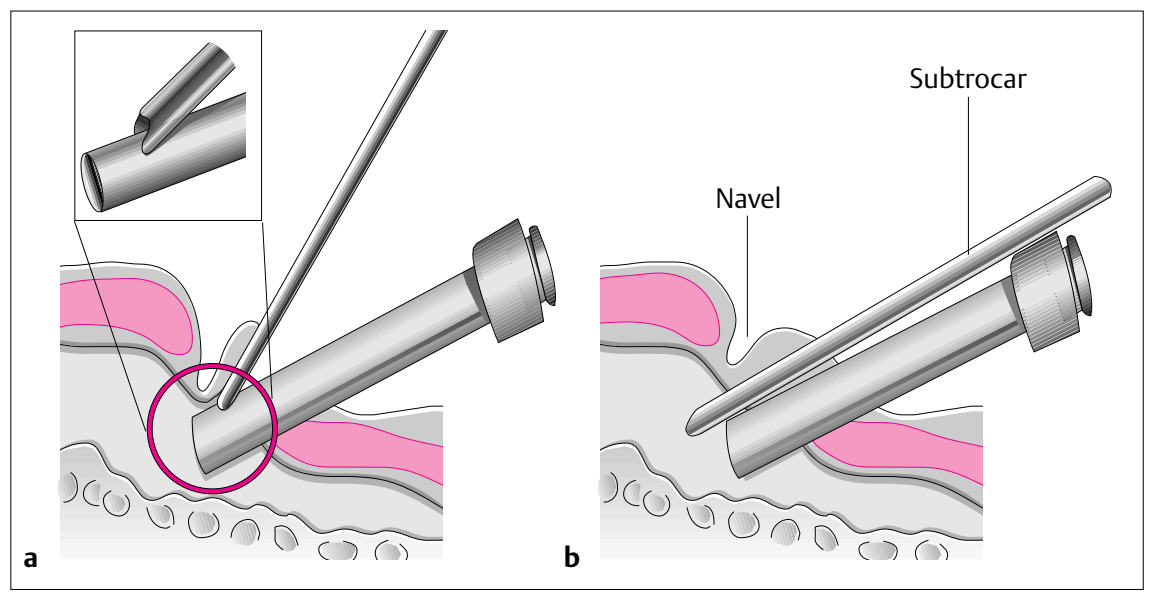

Figure 1 The subtrocar is made of stainless steel and is $200 \mathrm{~mm}$ in length and $7 \mathrm{~mm}$ in diameter. An ordinary $5 \mathrm{~mm}$ forceps can be inserted. The tip of the subtrocar is designed as shown in the inset and is shaped around the $10 \mathrm{~mm}$ reusable trocar to reduce the size when it is inserted into the abdominal cavity. a The subtrocar is inserted alongside the $10-\mathrm{mm}$ reusable trocar at the navel port site. $\mathbf{b}$ The navel site wound is bluntly dilated with the subtrocar and the subtrocar is positioned beside the $10 \mathrm{~mm}$ trocar. The air leak from the navel site wound is minimal

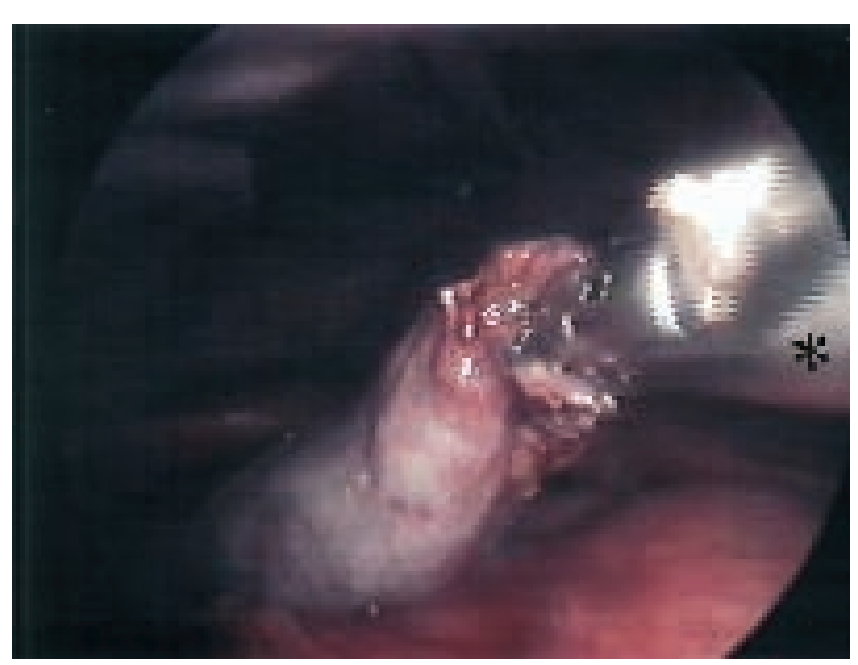

Figure 2 Extraction of the gallbladder from the abdominal cavity. A $5 \mathrm{~mm}$ forceps is inserted through the subtrocar ${ }^{*}$ ) and used to grasp the gallbladder. The view can be obtained when only the subtrocar is used

\section{References}

${ }^{1}$ Kimura T, Sakuramachi S, Yoshida M, et al. Laparoscopic cholecystectomy using fine-caliber instruments. Surg Endosc 1998; 12: 283-286

${ }^{2}$ Yuan RH, Lee WJ, Yu SC. Mini-laparoscopic cholecystectomy: a cosmetically better, almost scarless procedure. J Laparoendosc. Adv Surg Tech 1997; 7: 205-211

${ }^{3}$ Berci G. Laparoscopic cholecystectomy using fine-caliber instruments; smaller is not necessarily better. Surg Endosc 1998; 12: 197
Corresponding Author S. Kakizoe, M.D., Ph.D.

Dept. of Surgery

Kakizoe Hospital

Kagamigawa 278

Hirado

Nagasaki 859-5152

Japan

Fax: $\quad+81-950-225131$

E-mail: kakizoes@nagasaki.med.or.jp 